\title{
USERS-CENTRIC ADAPTIVE LEARNING SYSTEM BASED ON INTERVAL TYPE-2 FUZZY LOGIC FOR MASSIVELY CROWDED E-LEARNING PLATFORMS
}

\author{
Khalid Almohammadi $^{1}$, Hani Hagras ${ }^{1}$, Daniyal Alghazzawi ${ }^{2}$, Ghadah Aldabbagh ${ }^{1}$ \\ ${ }^{1}$ The Computational Intelligence Centre, School of Computer Science and Electronic Engineering \\ University of Essex, Colchester, UK \\ ${ }^{2}$ Information Systems Department, Faculty of Computing and Information Technology \\ King Abdulaziz University, Jeddah, Saudi Arabia \\ ${ }^{3}$ Computer Science Department, Faculty of Computing and Information Technology \\ King Abdulaziz University, Jeddah, Saudi Arabia
}

\begin{abstract}
Technological advancements within the educational sector and online learning promoted portable data-based adaptive techniques to influence the developments within transformative learning and enhancing the learning experience. However, many common adaptive educational systems tend to focus on adopting learning content that revolves around pre-black box learner modelling and teaching models that depend on the ideas of a few experts. Such views might be characterized by various sources of uncertainty about the learner response evaluation with adaptive educational system, linked to learner reception of instruction. High linguistic uncertainty levels in e-learning settings result in different user interpretations and responses to the same techniques, words, or terms according to their plans, cognition, pre-knowledge, and motivation levels. Hence, adaptive teaching models must be targeted to individual learners' needs. Thus, developing a teaching model based on the knowledge of how learners interact with the learning environment in readable and interpretable white box models is critical in the guidance of the adaptation approach for learners' needs as well as understanding the way learning is achieved.

This paper presents a novel interval type-2 fuzzy logic-based system which is capable of identifying learners' preferred learning strategies and knowledge delivery needs that revolves around characteristics of learners and the existing knowledge level in generating an adaptive learning environment. We have conducted a large scale evaluation of the proposed system via real-word experiments on 1458 students within a massively crowded e-learning platform. Such evaluations have shown the proposed interval type-2 fuzzy logic system's capability of handling the encountered uncertainties which enabled to achieve superior performance with regard to better completion and success rates as well as enhanced learning compared to the non-adaptive systems, adaptive system versions led by the teacher, and type-1-based fuzzy based counterparts.
\end{abstract}

Keywords: Type-2 Fuzzy Logic systems, e-learning, intelligent learning environments 


\section{Introduction}

Achieving student satisfaction and improving academic performance are the core objectives of education systems. Therefore, obtaining a precise and comprehensive understanding of the needs of every student based on their distinctive attributes, such as level of knowledge, learning style, and level of engagement is highly important. This is needed that teaching content, styles and strategies can be effectively adapted to suit every student. In the context of traditional classroom instruction, it is extremely difficult for teachers to know the main cause of low satisfaction, engagement and outcomes among the students, which makes it difficult for teachers to find solutions that facilitate the improvement of students' performance and attention while learning [1].

The occurrence of this problem can be attributed to the different levels of knowledge and motivation among students as well as the characteristics of teaching style and content adopted by teachers [1]. The different attributes wielded by students and the class size constrain the degree to which a teacher can adapt the learning environment to ideally suit all students simultaneously [1]. With smaller class sizes, it becomes easier for teachers to focus on the needs of every student, hence enhancing the accuracy of learning as well as the ability of teachers to evaluate the attributes of all students [1]. Myriad studies have concluded that one-to-one teaching fosters better learning outcomes, motivation and engagement levels [2], [3], [4]. However, it is basically impossible to espouse such an instructional style as a substantial component of teaching within traditional utilitarian classes.

Recently, e-learning courses have seen increased growth and popularity. There are over 30 million higher education students who take classes online, $50 \%$ of whom reside in the US. In the year 2011, it was revealed that around 16.1 million US students take at least one class online. This number is predicted to rise to around 41 million by 2016 [5]. Based on these statistics, it is evident that elearning has become increasingly essential and has turned into a key method through which higher education is provided [6]. However, e-learning environments also have numerous challenges. Some of these challenges are similar to those of conventional classes, especially with regard to lack of interaction.
Traditionally, e-learning courses were delivered using learning management systems that provided the educational content using the same structure and composition for all students [7], [8]. Because students have different attributes, this became a challenge because it hindered performance and engagement levels among students. In a bid to counter this challenge, adaptive educational learning technologies and environments are utilized [1]. Because adaptive learning systems provide instructional material based on the specific needs and preferences of each student, these systems have the ability to improve performance among students, and this has led to increased interest in such learning systems [8], [9].

There are several factors that impinge on the learning requirements and preferences among students, such as personality attributes, learning styles, motivation, knowledge level, attention span and goals [7]. These factors can be evaluated so as to make the instructional process adaptive through initiatives such as improving the manner in which content is presented and the sequencing of informational materials so that the needs of every student are catered to, thus helping them improve their performance as well as their completion rate for the course [10]. Thus, automatic and continuous learning preferred knowledge delivery needs and preferences for students are important factors for obtaining higher student learning outcomes, motivation and satisfaction. Our work also seeks to investigate how higher and precise adaption of the learning environment can obtain better outcomes and higher completion rate that results from the precision of the learned model.

The efficiency of adaptive educational systems is contingent on the mechanism applied in the collection of information with regard to students' learning needs as well as on the manner in which this information is processed to tailor adaptive learning environments [8]. However, how can we make sure of high precision in evaluating students' needs and knowledge level for provision of the optimal and precise adaptive course content?

This question is critical due to several sources of uncertainty in how accurately students' responses are assessed by adaptive educational methods as well as the corresponding uncertainties associated with how the resulting instruction to the 
student is actually understood and received. However, most of the exiting adaptive e-learning systems rely upon the ideas and knowledge of a few experts to guide the adaption process. As mentioned above, such views might be characterized by various uncertainty sources, particularly in the way learners' responses can be evaluated accurately through the suggested adaptive educational system, and the "corresponding uncertainties" linked to the way the emerging instruction toward the learner is received and understood. In e-learning settings, high linguistic uncertainty levels exist, whereby learners may arrive at interpretations and act upon the same techniques, words, or terms (for example, preferred learning strategy, study time length or course difficulty) in different ways depending on their plans, cognition, pre-knowledge and motivation levels [11]. Therefore, one adaptive teaching model, even when accompanied by designers' and experts' knowledge, might not serve all learners' needs. To tackle the uncertainty that may inhibit the advancement of an efficient learning context, it is suggested that all adaptive educational systems should incorporate a flexible Artificial Intelligence (AI) method [11].

There are several AI-based approaches that have been implemented with the aim of achieving an efficient adaptive educational system. However, most of the AI approaches that have been implemented are not capable of learning from the behavioural tendencies of the user so as to generate easy to read and understand white box models capable of dealing with these uncertainties. Fuzzy logic systems are reputed for their ability to generate white box models that are capable of dealing with high-level uncertainties. Nonetheless, most fuzzy logic systems use type-1 fuzzy logic whose capability of dealing with an uncertainty is based on precise type-1 fuzzy sets [12]. On the contrary, interval type-2 fuzzy logic systems are capable of dealing with uncertainty using interval type-2 fuzzy sets that are inclusive of a footprint of uncertainty (FOU), the purpose of which is to augment the degree of freedom so as to improve the system's ability to deal with high-level uncertainties [12].

In this paper, a system that is based on type-2 fuzzy logic is presented. The system has the ability of learning the preferred knowledge delivery needs of users with regard to their attributes, hence gen- erating an adaptive learning environment. The development of the type-2 fuzzy model is based on data collected from several students who have different aptitudes and needs. The model was then implemented to enhance the delivery of knowledge to different students based on their individual attributes and knowledge levels. This paper will explain the manner in which the system can customize the learning environments so as to improve the delivery of knowledge to students of different attributes, which can, in turn, improve student performance, motivation and engagement level. The system proposed in this paper has the ability to continuously learn, respond, and adapt to the needs of every student. As a result, it can be implemented in online courses to deliver adaptive education content to students with varying needs. The proposed system was tested using various real-world experiments within a massively crowded e-learning platform that involved 1458 students from King Abdulaziz University. The experiments showed that the proposed system has a better capability of dealing with the uncertainties and improving performance and course completion rate in comparison with nonadaptive systems, adaptive system versions led by the instructors, as well as type-1-based fuzzy logic systems counterparts.

The paper is organized as follows: Section 2 presents a brief overview on some AI techniques that are employed for adaptive educational systems. In section 3, an overview on type-2 fuzzy logic systems is provided. Section 4 provides an overview on the application of fuzzy logic systems to education and e-learning platforms. Section 5 presents the proposed users-centric adaptive Learning System based on Interval Type-2 Fuzzy logic System (IT2FLS) for massively crowded E-learning platforms. Section 6 presents the experiments and results while the conclusions and future work are presented in Section 7.

\section{A Brief Overview on Some AI techniques that are Employed for Adaptive Educational Systems}

The ability of AI approaches to learn and replicate the decision-making process espoused by students makes them valuable tools in adaptive edu- 
cational systems [13]. There are various AI techniques that have been used in adaptive educational systems such as fuzzy logic, Bayesian networks, neural network and hidden Markov models. There are various ways through which AI approaches are used in adaptive educational systems. For example, in some systems the core focus is to examine and assess students' characteristics so as to generate profiles of the students with the intention of evaluating their overall level of knowledge [10], [14], [15], [16], [17], [18], [19]. AI approaches are also used to facilitate the diagnostic processes' completion so that course content can be adjusted to cater to the needs of every student [15], [16], [20], [21], [22], and [23]. However, some AI approaches, such as hidden Markov models, Bayesian networks, and neural networks are black box models which have a knowledge problem that makes them incapable of establishing human behaviour frameworks that are transparent and easy to analyze. Another limitation of these approaches is that they need the repetition of long iterative learning methods during the amendment of the framework, which is particularly challenging because the e-learning process is ever changing and dynamic [15].

\section{A Brief Overview of Type-2 Fuzzy Logic Systems}

As illustrated in Figure 1a, the interval type-2 fuzzy logic system (FLS) utilizes interval type-2 fuzzy sets (e.g., the type-2 fuzzy set illustrated in Figure $1 b)$ in the representation of the inputs and outputs. The third dimension values in the interval type- 2 fuzzy sets are all equal to one. Unlike the general type-2 FLS, computation is simplified when an interval type-2 FLS is used [12].

The functioning of the interval type-2 FLS is as follows: the first step is to fuzzify the crisp inputs into input type-2 fuzzy sets. The ease and suitability of singleton fuzzification makes it preferable for interval type-2 FLS. Afterwards, the inference engine and the rule base are activated by the input type- 2 fuzzy sets and this leads to the generation of output type- 2 fuzzy sets. The type- 1 and type2 FLS rule base are the same but the membership functions (MFs) of the type-2 FLS are represented by interval type- 2 fuzzy sets in the place of type- 1 fuzzy sets. The fired rules are combined by the in- ference engine, which then gives a mapping from input type- 2 to output type-2 fuzzy sets. The typereducer then processes the type-2 fuzzy output and combines the output sets to execute centroid calculations to produce type-1 fuzzy sets that are referred to as type-reduced sets. Type-reduction can be executed using various methods, but this paper focuses on the centre of sets type-reduction because of its reasonable complexity of computations [12]. Typereduction is then followed by defuzzification of the type-reduced sets so that the crisp outputs can be obtained. A detailed and comprehensive coverage of interval type-2 FLS can be found in [12].

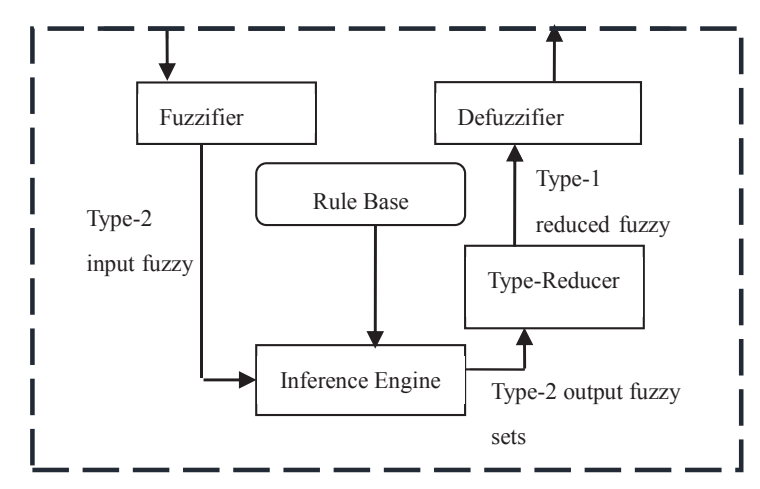

(a)

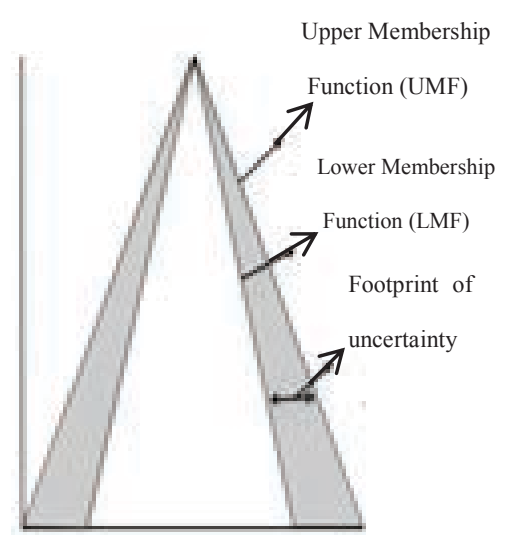

(b)

Figure 1. (a) Structure of the type-2 FLS [25], (b) An interval type-2 fuzzy set

The shaded area in Figure 1b) is labelled as Footprint of Uncertainty (FOU) which is bounded by lower membership function $\tilde{A}(x)$ and an upper membership function $\tilde{A}(x)[12]$. Thus an interval type-2 fuzzy set is written as follows:

$$
\tilde{A}=\int_{x \in X}\left[\int_{u \in[\tilde{A}(x), \tilde{\tilde{A}}(x)]} 1 / u\right] / x
$$




\section{Brief overview on the Application of Fuzzy Logic Systems in Educa- tion and E-learning Platforms}

A FLS can be implemented to facilitate the formation of a summary of the students' preferences pertaining to knowledge acquisition and understanding [11]. A FLS-based framework that is geared towards customization facilitates easy reasoning for both the users and designers, which in turn eases the process of content comprehension as well as system amendments [25], [26]. In addition, FLSs can also be used in the examination and assessment of learning and knowledge outcomes [17], [18], [19], [27]. Consequently, as previous studies established [17], [18], [19], [27], FLSs can be designed to facilitate the evaluation of task objectives and multiple criteria. However, FLSs are rarely used for the adaptive presentation of educational materials. In [20], a profiling system that uses a multi-agent approach for the creation of fuzzy models for content and students is done on the basis of a dynamic plan that is defined in advance for one individual. The development of this framework was done using profile abstraction, whereby a comparison of student-centred learning tasks, such as the topic, and the time spent on the topic, was conducted.

The creation of the content framework was done based on the fuzzy links between the subjects and the individuals' level of knowledge (these links were referred to as prerequisite relations). The prerequisite relations were used in the determination of the most appropriate learning plan (i.e., the order in which an individual should examine issues [20]). However, the estimation of student behaviours in this study was achieved using criterion links between the knowledge of the student and the topics, so as to come up with a dynamically grounded learning plan for the learners. In [20], students' needs were not learned automatically. In addition, the system in [20] did not have the adaptation features of a continuous learning approach that can facilitate easy amendments of the frameworks to suit the continuously evolving student preferences. Furthermore, to the best of our knowledge no studies have delved into the implementation of type-2 fuzzy approaches in adaptive learning educational environments.

\section{The Proposed User-Centric Adaptive Learning System Based on Interval Type-2 Fuzzy logic for Massively Crowded E- learning Platforms}

The objective of our proposed interval type-2 fuzzy logic, is to acquire knowledge about and dovetail several instructional variables, such as the suited current level of difficulty of the content along with the required time for learned content that has the ability to tackle the present condition of different learners' variables according to their present knowledge level and characteristics. The proposed environment will start its work flow at the application layer where the e-learning environments (course contents) and learners get to interact with each other.

First, this layer solely concentrates on specifying the required instructional variables needed to learn the outputs of the learning environment that are parallel with the learner variables or the inputs. Next, this layer will install a system of active recording and supervision of the specified data in relation to the teaching-learning behaviors (i.e., outputs and inputs of the system) generally seen in online learning environments. To generate systemlearned rules, a layer of learning fuzzy rules will then receive those inputs and outputs. This layer aims at first extracting interval type-2 fuzzy sets in relation to system output and input on the basis of creating type- 2 fuzzy sets and method centering on methodology detailed in [28], [29], [30], [31], out of a sample of respondents (30 students in the case of the conducted experiments) for managing linguistic uncertainty. Having gathered data (one week is needed in the case of conducting experiments) and accumulated the fuzzy sets, the system will enter the state of building fuzzy rules with the purpose of detailing the most required instructional actions having the satisfactory present conditions of student capabilities and characteristics based on an unsupervised one-pass approach, as motivated through [32], [33], [34].

Finally, the adaption layer will be utilized; this is where the students' current learning inputs states are taken and given suitable outputs to accomplish their learning tasks. Our proposed environment will 
further enable the online adaption and enhancement of rules in this layer. This facilitates long-term learning due to the changing of the performance, capabilities, delivery instructional preferences and needs of the students. The advocated environment comprises the following three layers (as shown in Figure 2) which will be explained in the following subsections.

\section{Application Layer}

\section{The Fuzzy Rules Learning Layer}

3. The Online Adaption and Lifelong Learning Layer

\subsection{Application Layer}

The main purpose of this layer is to first specify the learners' variables, which are the inputs according to the system outputs; these are related to the content or instructional variables to be learned. Instructional variables could be the suitable learning content difficulty level and time needed, along with the preferred learning style and method of knowledge acquisition. These variables promote the student learning level that matches the current learner variables, which include the student's current level of knowledge and other personal characteristics related to the adaptation process, making it more personalized.

\subsubsection{The Observer Component}

Student data are first collected and captured by evaluating the students' knowledge delivery requirements with the preferred learning style, alongside the characteristics of the online learning environment. Significantly, the data (present outputs and inputs) will be actively recorded upon the change of the knowledge delivery needs or characteristics. Therefore, a descriptive model of the students' knowledge delivery needs and characteristics is created and learned by our system; this is achieved through the data gathered, generating a set of multiinput and output data pairs, which take the following form [32], [33], [34]:

$$
x^{(t)} ; y^{(t)} \quad(t=1,2, \ldots, N),
$$

where $N$ is recognized as the number of data instances, $x^{(t)} \in R^{n}$, and $y^{(t)} \in R^{k}$. The impact of the input variable $y=\left(y_{1}, \ldots, y_{k}\right)^{T}$ upon the $k$ output knowledge delivery variables $x=\left(x_{1}, \ldots, x_{n}\right)^{T}$ are explained by the rules that are extracted by our system. With specific consideration of the experiments conducted within the online learning environment, seven student characteristics' variables were utilized for the inputs, and 4 knowledge delivery needs (which will be detailed later) variables were utilized for the outputs. A correlating model of the inputs and outputs is achieved by the established fuzzy rules without requiring a mathematical model. Therefore, individual rules can be adapted online, affecting only certain aspects of the descriptive model created and learned by the proposed system.

\subsection{The Fuzzy Rules Learning Layer}

\subsubsection{Extracting the Interval Type-2 Fuzzy Sets}

Categorization of collected data input and output is essential through specific functions of fuzzy membership. In this way, input and output values are quantified and converted into linguistic labels such as high, very high, low and very low. The details of the implemented approach are found in [28], [29], [30], [31] and cause the creation of the FOU and a type-2 fuzzy set, where several type-1 fuzzy sets are embedded to signify the individual perceptions of every student regarding a specific linguistic label that elaborates requirements, preferences and features. Consequently, different students' opinions regarding the modelling of words will be combined by FOU generated from type- 2 fuzzy sets, and the uncertainties will also be managed.

The applied approach accumulates data via asking questions to the respondents regarding their perspectives on the linguistic labels, by which the type1 fuzzy sets will be generated. Following this stage, utilizing the approach of [28], [29], [30], [31], the type-2 fuzzy sets are constructed where the type1 fuzzy sets (representing the students' individual preferences) are combined, resulting in the FOU of the type-2 fuzzy set, which represents the given word. By applying the representation theorem [12], [28], [29], [30], [31] the calculation of each interval type-2 fuzzy set $\tilde{A}_{s}$ will be:

$$
\tilde{A}_{s}=\bigcup_{i=1}^{n} A^{i}
$$




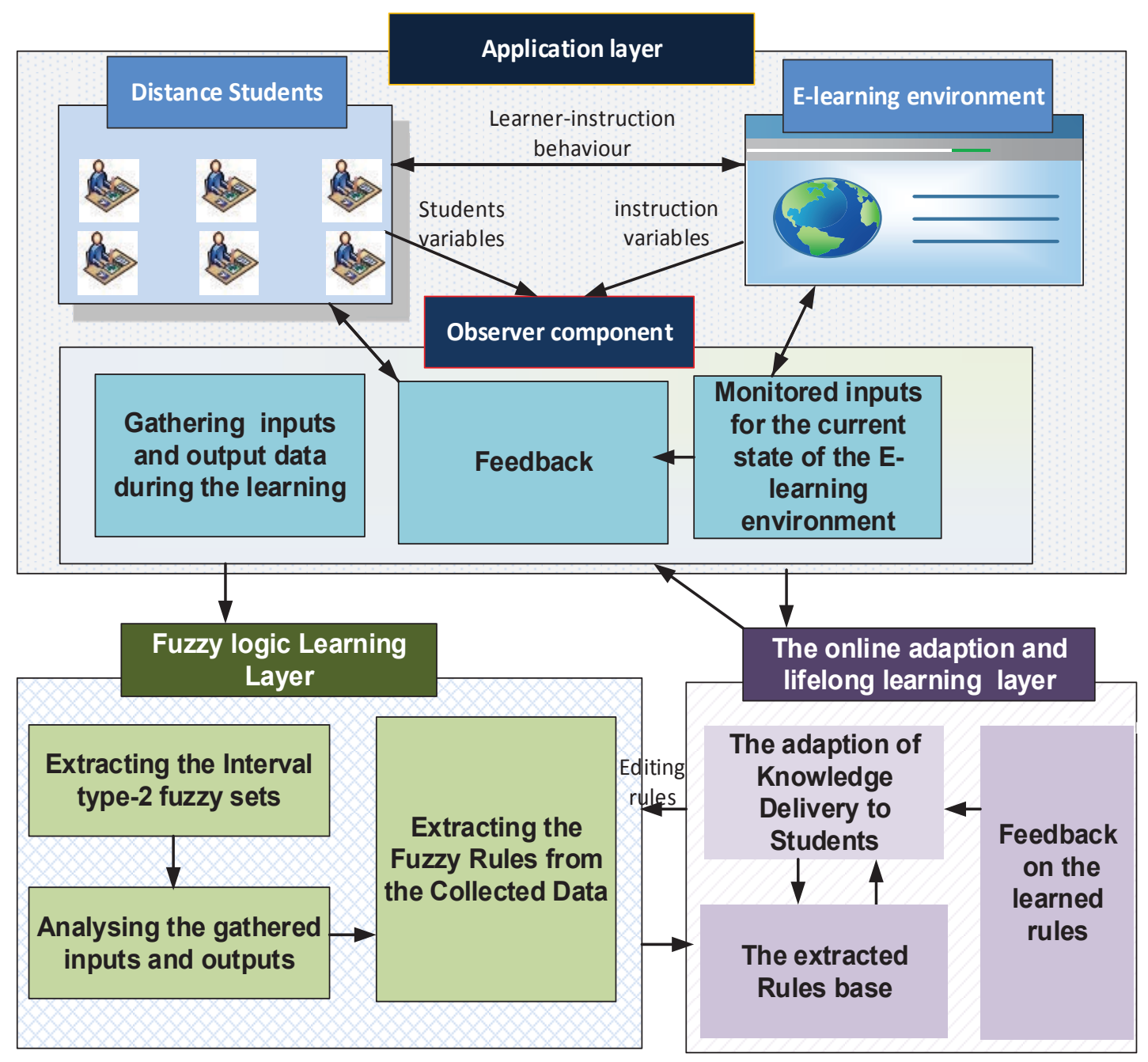

Figure 2. An overview on the proposed users-centric adaptive Learning System based on Interval Type-2 Fuzzy logic for massively crowded E-learning platforms 
Here, $i^{\text {th }}$ type- 1 fuzzy set and $\cup$ is an operation of aggression [28], [29], [30], [31] embedded in the reference of $A^{i}$. Approximations of lower $\mathrm{MF}_{\tilde{A}}(x)$ of $\tilde{A}_{s}$ and upper $\mathrm{MF}_{\tilde{A}}(x)$ serve as the basis of generating the process of $\tilde{A}$. This will depend on the shape of the embedded type- 1 fuzzy sets and the FOU model, which is to be generated for $\tilde{A}_{s}$. In our system, we use interior FOU models and right and left shoulder MFs (shown in Figure 3a, Figure $3 \mathrm{~b}$ and Figure $3 \mathrm{c}$ ) for the upper and lower MF parameters from all the embedded non-symmetric triangular type-1 MFs. As shown in Figure 3a, the resulting interior interval type-2 fuzzy set is described by parameters $\underline{a}_{M F}, \underline{c}_{M F}, \bar{c}_{M F}$, and $\bar{b}_{M F}$ denoting a trapezoidal upper MF and parameters $\bar{a}_{M F}$ and $\underline{b}_{M F}$ for a non-symmetric triangular lower MF, with an intersection point $(p, p)$ [28], [29], [30], [31]. The calculating processes for these parameters are detailed below.

The steps given below are required for upper $\mathrm{MF}_{\tilde{A}}(x)$ :

1. $\underline{a}_{M F}$ and $\bar{b}_{M F}$ should be found out equal with the minimum $a_{M F}^{\min }$ of all left-end points $a_{M F}^{i}$ and maximum $b_{M F}^{\max }$ of all right-end points $b_{M F}^{i}$ [28], [29], [30], [31], respectively, for $(x)=0$.

2. $\underline{c}_{M F}, \bar{c}_{M F}$ should be calculated corresponding to the type-1 MFs with maximum and minimum centres for $(x)=1$.

3. Approximate the upper $\mathrm{MF}_{\tilde{A}}(x)$ by connecting the following points with straight lines: $\left(\underline{a}_{M F}, 0\right),\left(\underline{c}_{M F}, 1\right),\left(\bar{c}_{M F}, 1\right)$, and $\left(\bar{b}_{M F}, 0\right)$. The result is a trapezoidal upper MF, as depicted in Figure 3a.

The lower $\operatorname{MF}_{\tilde{A}}(x)$ is approximated through the following steps:

1. $\bar{a}_{M F}$ and $\underline{b}_{M F}$ should be calculated equal with the maximum $a_{M F}^{\max }$ of all left-end points $a_{M F}^{i}$ and minimum $b_{M F}^{\min }$ of all right-end points $b_{M F}^{i}$ [28], [29], [30], [31].

2. The formulas below are to be used for computing the intersection point $(p, p)$ :

$$
\begin{gathered}
p=\frac{\underline{b}_{M F}\left(\bar{c}_{M F}-\bar{a}_{M F}\right)+\bar{a}_{M F}\left(\underline{b}_{M F}-\underline{c}_{M F}\right)}{\left(\bar{c}_{M F}-\bar{a}_{M F}\right)+\left(\underline{b}_{M F}-\underline{c}_{M F}\right)} \\
p=\frac{\left(\underline{b}_{M F}-p\right)}{\left(\underline{b}_{M F}-\underline{c}_{M F}\right)}
\end{gathered}
$$

An approximation of the lower $\operatorname{MF}_{\tilde{A}}(x)$ is to be executed by linking the points of $\left(\underline{a}_{M F}, 0\right),\left(\bar{a}_{M F}, 0\right)$, $(p, p),\left(\underline{b}_{M F}, 0\right)$ and $\left(\bar{b}_{M F}, 0\right)$ through a direct line. As depicted in Figure 3a, which is a triangle lower MF.

The method adopted for computing the FOU for the right and left shoulder is similar to that described in [28], [29], [30], [31]. The computation of the upper MF $\tilde{A}(x)$ that concerns the left shoulder (referred to in Figure $3 b$ ) requires joining of the points $(0,1),\left(\underline{a}_{M F}, 1\right),\left(\underline{b}_{M F}, 0\right)$, and $\left(\bar{b}_{M F}, 0\right)$ with straight lines. The computation of the lower $\operatorname{MF}_{\tilde{A}}(x)$ requires joining of the points $(0,1),\left(\underline{a}_{M F}, 1\right),\left(\underline{b}_{M F}, 0\right)$ and $\left(\bar{b}_{M F}, 0\right)$ with straight lines. Likewise, as is shown in Figure $3 \mathrm{c}$, the estimation of MF $\tilde{A}(x)$ that concerns the right shoulder requires joining of the points $\left(\underline{a}_{M F}, 0\right),\left(\underline{b}_{M F}, 1\right)$, and $(M, 1)$ with straight lines. The approximation of the lower $\operatorname{MF}_{\tilde{A}}(x)$ requires joining of the points $\left(\underline{a}_{M F}, 0\right),\left(\bar{a}_{M F}, 0\right),\left(\bar{b}_{M F}, 1\right)$, and $(M, 1)$ with straight lines [28], [29], [30] and [31].

\subsubsection{Extracting the Fuzzy Rule from the Col- lected Data}

To extract the rules that delineate the individual behaviours, data collected from the output or input and the generation of interval type-2 fuzzy sets are combined with each other. An improved approach of the Wang-Mendel method is the basis of the applied method of rule extraction [32], [33] and [34].

Several rules of multiple-input-multiple-output are extracted via the proposed type-2 fuzzy system and are recognized as explaining the association between $x=\left(x_{1}, \ldots, x_{n}\right)^{T}$ and $y=\left(y_{1}, \ldots, y_{k}\right)^{T}$, adopting the following form:

$$
\begin{gathered}
I F x_{1} \text { is } \tilde{A}_{1}^{l} \ldots \text { and } x_{n} \text { is } \tilde{A}_{n}^{l} \text { THEN } y_{1} \text { is } \tilde{B}_{1}^{l} \\
\quad l=1,2, \ldots, M
\end{gathered}
$$

Here, $M$ and $l$ represent the number of rules and the index of the rules, respectively.

There are particular explanations of $V_{i}$ interval type-2 fuzzy sets $\tilde{A}_{s}^{q}, q=1, \ldots, V_{i}$ that correspond to each input $x_{s}$, having $s=1,2, \ldots, n$. There are also explanations of $V_{o}$ interval type-2 fuzzy sets $\widetilde{B}_{c}^{h}, h=1, \ldots, V_{o}$ that correspond to each output $y_{c}$, where $c=1,2, \ldots, k$. 


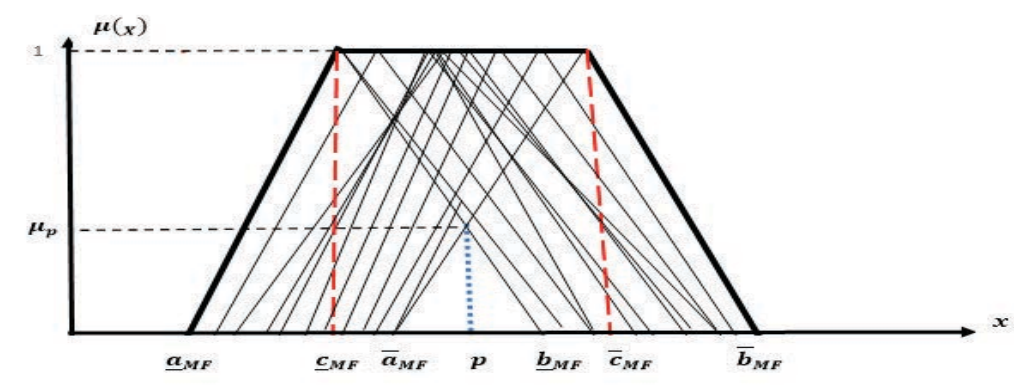

(a)

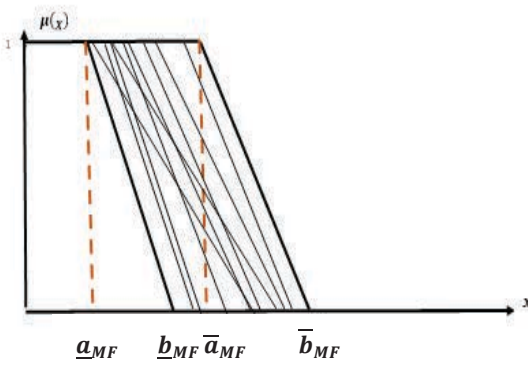

(b)

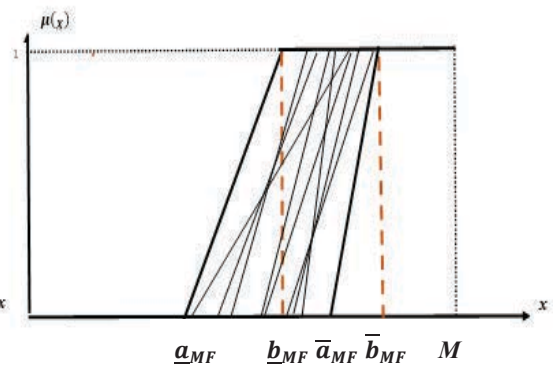

(c)

Figure 3. (a) An interior type-2 MF embedding the different type-1 fuzzy sets, (b) left shoulder type-2 MF embedding the different type-1 fuzzy sets, (c) right shoulder type-2 MF embedding the different type-1 fuzzy sets [28], [29], [30], [31]

The attempt to explain and summarize the following representation of the approach should consist of rules with a single output whose demonstration owes to the relative simplicity of the method in the case of expanding the rules that engage several outputs. The stages of rule extraction are explained below.

Stage 1: In case of a pair of fixed input-output data $\left(x^{(t)} ; ; y^{(t)}\right)$ from the dataset $(t=1,2, \ldots, N)$, the computations of the values for upper and lower membership are $\tilde{A}_{s}^{q}\left(x_{s}^{(t)}\right)$ and $\tilde{A}_{s}^{q}\left(x_{s}^{(t)}\right)$, corresponding to each fuzzy set $\tilde{A}_{s}^{q}, q=1, \ldots, V_{i}$ and each input variable $s(s=1, \ldots, n)$. Find $q^{*} \in\left\{1, \ldots, V_{i}\right\}$ such that [32], [33], and [34]:

$$
\tilde{A}_{s}^{c g}\left(x_{s}^{(t)}\right) \geq \tilde{A}_{s}^{q g}\left(x_{s}^{(t)}\right)
$$

For all $\mathrm{q}=1, \ldots, V_{i}, \underset{\tilde{A}_{s}^{q}}{c g}\left(x_{s}^{(t)}\right)$ is the centre of gravity of the interval membership of $\tilde{A}_{s}^{q}$ at $x_{s}^{(t)}$, as can be seen below [12]:

$$
\tilde{A}_{s}^{q g}\left(x_{s}^{(t)}\right)=\frac{1}{2}\left[\tilde{A}_{s}^{q}\left(x_{s}^{(t)}\right)+\tilde{A}_{s}^{q}\left(x_{s}^{(t)}\right)\right.
$$

The following rule will be referred to as the rule generated by $\left(x^{(t)} ; ; y^{(t)}\right)$ [32], [33] and [34]:

$I F x_{1}$ is $\tilde{A}_{1}^{q^{*(t)}}$ and $x_{n}$ is $\tilde{A}_{n}^{q^{*(t)}}$ THEN $y$ is centered at $y^{(t)}$
For all of the input variables $x_{s}$, there are $V_{i}$ type-2 fuzzy sets $\tilde{A}_{s}^{q}$, which enable a greater number of potential rules equal to $V_{i}^{n}$. However, when considering the dataset, there will be the generation of those rules among the $V_{i}^{n}$ possibilities that show a dominant region comprising a minimum of one data point.

At this stage, one rule is created, and this rule corresponds to every concerned pair of inputoutput data, including the selected fuzzy set, in terms of achieving a higher membership value at the data point. More importantly, it has been chosen to serve the $I F$ element of the rule. However, this version of the rule is not the final version of the rule, which will be calculated in the subsequent step. Particularly, the rule weight is computed as the following [32], [33], and [34]:

$$
w i^{(t)}=\prod_{s=1}^{n} \tilde{A}_{s}^{q g}\left(x_{S}(t)\right)
$$

The rule $w i^{(t)}$ weight can be defined as the measurement of the strength of the points $x^{(t)}$ belonging to the fuzzy region that the entire rule encompasses.

Stage 2: The first stage is repeated in this stage for all the data points $N$ from 1 and $n$ data generated rules are obtained by it, as in eq. (9) form. Due to various similar examples contained in a number 
of data points, multiple rules are created in Stage 1 with similar IF parts and their accumulation evolving from a single rule. Therefore, two groups are formed for rules $N$ comprising similar IF parts in each group. If the number of such groups is assumed to be $M$, then the presence of $N_{l}$ rules in the group can be implied, hence [32], [33] and [34]:

IF $x_{1}$ is $\tilde{A}_{1}^{l} \ldots$ and $x_{n}$ is $\tilde{A}_{n}^{l}$ THEN $y$ is centered at $y^{\left(t_{u}^{l}\right)}$

Here, the group index $l$ comprises $u=$ $1, \ldots, N$ and $t_{u}^{l}$. The following calculation is the weighted average of all involved rules in the conflict group [32], [33] and [34]:

$$
a v^{(l)}=\frac{\sum_{u=1}^{N_{l}} y^{\left(t_{u}^{l}\right)} w i^{\left(t_{u}^{l}\right)}}{\sum_{u=1}^{N_{l}} w i^{\left(t_{u}^{l}\right)}}
$$

A single rule is formed from these $N_{l}$ rules, for which the following format is utilized [32], [33], and [34]:

$$
\text { IF } x_{1} \text { is } \tilde{A}_{1}^{l} \ldots \text { and } x_{n} \text { is } \tilde{A}_{n}^{l} \text { THEN } y \text { is } \tilde{B}^{l}
$$

where the output fuzzy set $\tilde{B}^{l}$ is selected on the basis of the following among the $V_{o}$ output interval type2 fuzzy sets $\tilde{B}^{l}, \ldots, \tilde{B}^{V_{o}}$. Find $B^{h *}$ such that [32], [33] and [34]:

$$
\begin{gathered}
c g \\
\tilde{B}^{c k}\left(a v^{(l)}\right) \geq \widetilde{B}^{c g}\left(a v^{(l)}\right) \\
\text { for } h=1,2 \ldots, V_{o}
\end{gathered}
$$

$\tilde{B}^{l}$ is chosen due to the $B^{h *}$, where ${ }_{\tilde{B}^{h}}^{c g}$ is the centre of gravity of the interval membership of $\tilde{B}^{h}$ at $a v^{(l)}$ as illustrated in Equation (8).

Therefore, we can conclude that our system controls input-output data pairs with numerous outputs. Regarding the number of outputs related to every rule, Step 1 can be called distinctive, whereas straightforward expansion aimed at facilitating rules while covering numerous outputs is provided by Step 2, as the calculation details are given in the repetition of the Eq. (12-14).

\subsection{The Online Adaption and Lifelong Learning Layer}

\subsubsection{The customization of knowledge delivery to students}

The fuzzy rules extracted through the collected input and output data of students and the extracted membership functions facilitate the proposed system for establishing and learning the characteristics and requirements of knowledge delivery to students. Then, the system will be in a position to make changes to the online learning environment with particular consideration to the needs and preferences of the students. The system response is triggered through the monitoring of student variables, which cause an impact to be felt by the online learning environment, especially in regard to the learned approximation of students' individual needs and preferences.

Our proposed type-2 fuzzy logic adaptive environment works as follows:

- The crisp inputs which encompass the characteristics of the student (detailed in the e-learning environment) are fuzzified into the input interval type-2 fuzzy sets (singleton fuzzification).

- The inference engine and rule base are activated, which creates the output (student requirements) type-2 fuzzy sets.

- The inference engine outputs are processed by type-reduction to produce type-reduced sets.

- The type-reduced type-1 fuzzy outputs are then defuzzified to create crisp outputs.

- The crisp outputs are then fed to the outputs.

\subsubsection{The adaptive online lifelong learning mechanism for dynamically updating content selection and display for users}

It is important for the suggested system to enable the modification to the changing needs and constantly expand the knowledge level of the students by giving them the ability to modify their learning needs and preferences. Then the system can modify its rules or apply new ones accordingly. In case of a given inputs, no rules fire from the rule base (i.e. the rule's firing strength in Eq. (10) $w i^{(t)}=0$ ), the system will record the system input and will capture the user preferred knowledge delivery to create a rule which can cover this uncovered input status. Therefore, the system will integrate new rules when the state of the online learning environment monitored at that time is indeterminate according to the present rules in the rules base (i.e. where 
none of the present rules are fired). In such an instance, new rules will be devised and added by the system, whereby the antecedent sets highlight the online environment's present input states, with the consequent fuzzy sets reliant on the current state of knowledge delivery needs and preferences. For all of the input parameters $x_{s}$ the fuzzy sets that provide membership values, where ${\tilde{A_{c}^{h}}}_{c}^{c g}\left(x_{s}^{\left(t^{\prime}\right)}\right)>0$ are identified. As a result, this creates a number of identified fuzzy $\operatorname{set}(\mathrm{s})$, in the form of a grid, for each input parameter. From such a grid, there is the construction of new rules based on all individual combinations of successive input fuzzy sets. The consequent fuzzy set that provides the greatest value of membership to the student defined knowledge delivery needs $\left(y_{c}\right)$ is accordingly chosen to act as the generated rule consequent. The resulting fuzzy sets can be established through conducting a computation of the output interval memberships' centre of gravity [32], [33] and [34]:

$$
\underset{\widetilde{B}_{c}^{h^{*}}}{c g}\left(y_{c}\right) \geq \underset{\widetilde{B}_{c}^{h}}{c g}\left(y_{c}\right)
$$

For $h=1, \ldots, W$ the $\tilde{B}_{c}$ is chosen as $\tilde{B}_{c}^{h^{*}}$, where $c=1, \ldots, k$. This enables the gradual adding of new rules to the rule base.

In case the user makes a change of preference or needs the knowledge delivery at a given input status, the fired rules will be selected and the consequent rules will be changed (if more than two users signal the same knowledge delivery preference and need), as shown by Eq. (15). Therefore, the fired rules are adapted to more suitably reflect the updated knowledge delivery requirements of the students, considering the present state of the online learning environment. The system proposed in this paper adopts life-long learning through facilitating the adaptation of rules according to the dynamic students delivery needs, which notably change over time based on students expanding knowledge and needs in regard to the state of the online learning environment. Owing to the system flexibility, the fuzzy logic model learned initially may be effortlessly expanded in order to make changes to both new and existing rules. These fuzzy rules enable a large range of values for all parameters (input and output) to be captured, which in turn enables the continuation of the generation of rules, even when the online learning environment gradually changes.

\section{Experiment and Results}

Various real-world experiments were conducted within a massively crowded elearning platform encompassing 1,458 students from King Abdulaziz University in Saudi Arabia. To perform the experiments, we customized the online learning platform to teach the Microsoft Excel and PowerPoint modules approved by King Abdulaziz University. This platform was used as a test bed for the proposed systems. Twelve learning units in Excel and nine learning units in PowerPoint were designed, each containing different lessons. A full explanation of each of these learning units was taken from the approved course structure and contents from King Abdulaziz University, as shown in Figures 4 and 5.

Each lesson included the following five main features (see Figure 6): A text explanation of the course content, demonstration through which students can see a practical application, practical exercise, a video from the lecturer and an assessment exercise. The details and screen captures of these features is detailed below.

1. A text explanation of the course content from the lesson was compiled into PowerPoint slides. This explanation was designed for each lesson and was taken from the approved course content of King Abdulaziz University, such as the lesson for creating a pie chart and line chart, as shown in Figure 7.

2. Demonstration through which students can see a practical application of what they have learned from the lesson. This is shown in Figure 8, where the steps for creating a pie chart are demonstrated to the students with explanation such as "First, we first select the range of cells. Then by clicking the Insert tab, from the Charts group, choose Pie, and select the suited Pie chart," This is shown in the following figure (Figure 8).

3. Practical exercise through which students can work on developing specific skills related to the lesson. When students respond incorrectly, the system provides hints for the correct answer, such as in the case of the lesson "Changing the Sheet Direction." For this lesson, the students are required to change the direction of the page from right to left. They should first click on the 


$$
\text { مهازات الحاسبب الآلثي }
$$

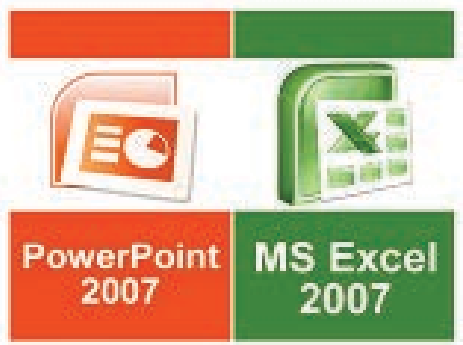

Figure 4. The main interface of the developed online learning system

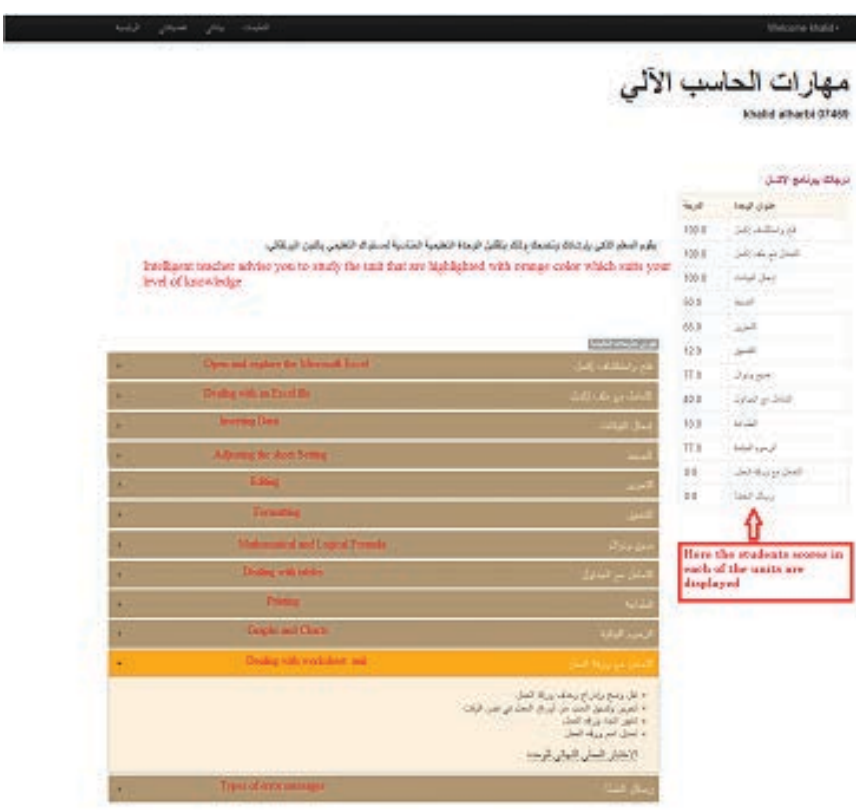

Figure 5. The learning units designed for both Excel and PowerPoint

W

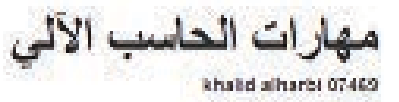

Ivit: Graphs aat Chass

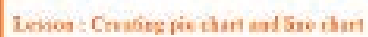

stowinting

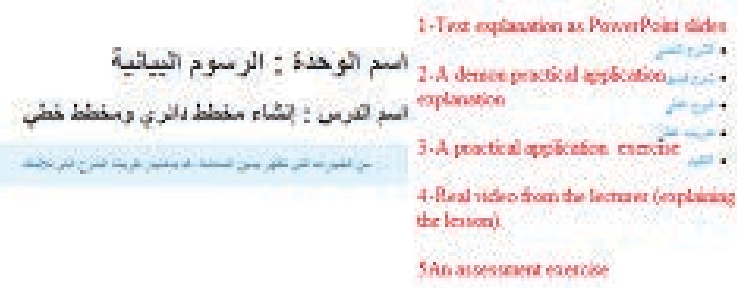

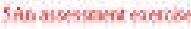

Figure 6. The main lesson interface 


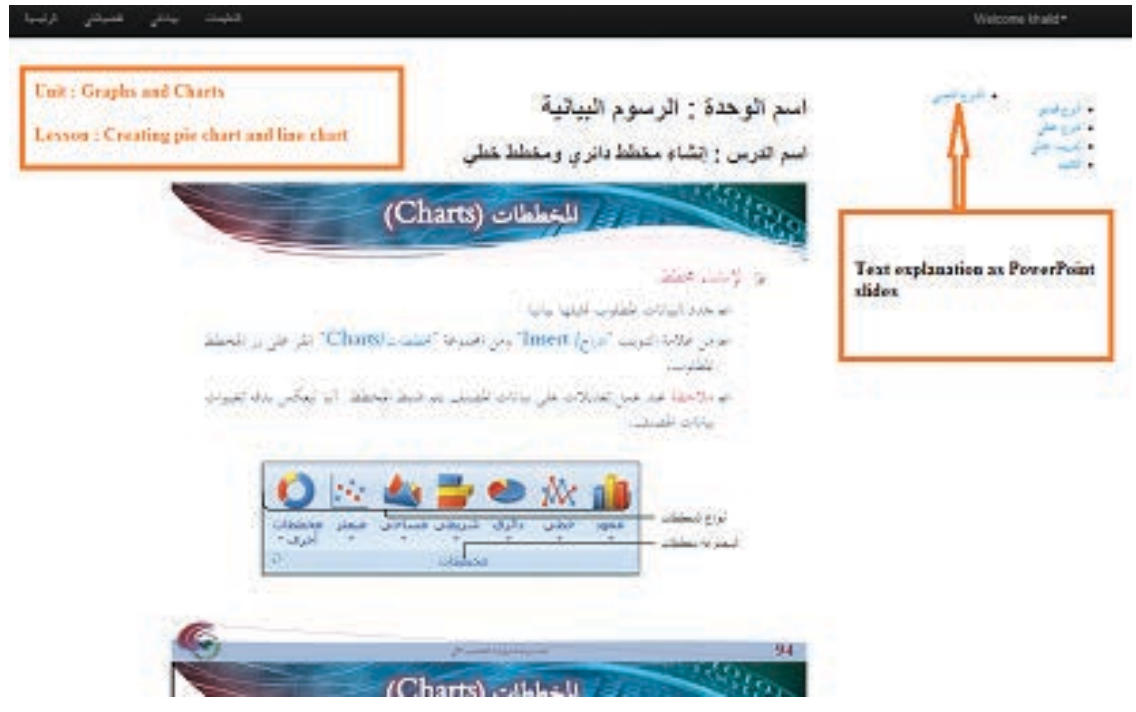

Figure 7. Text explanation interface for creating the pie chart lesson

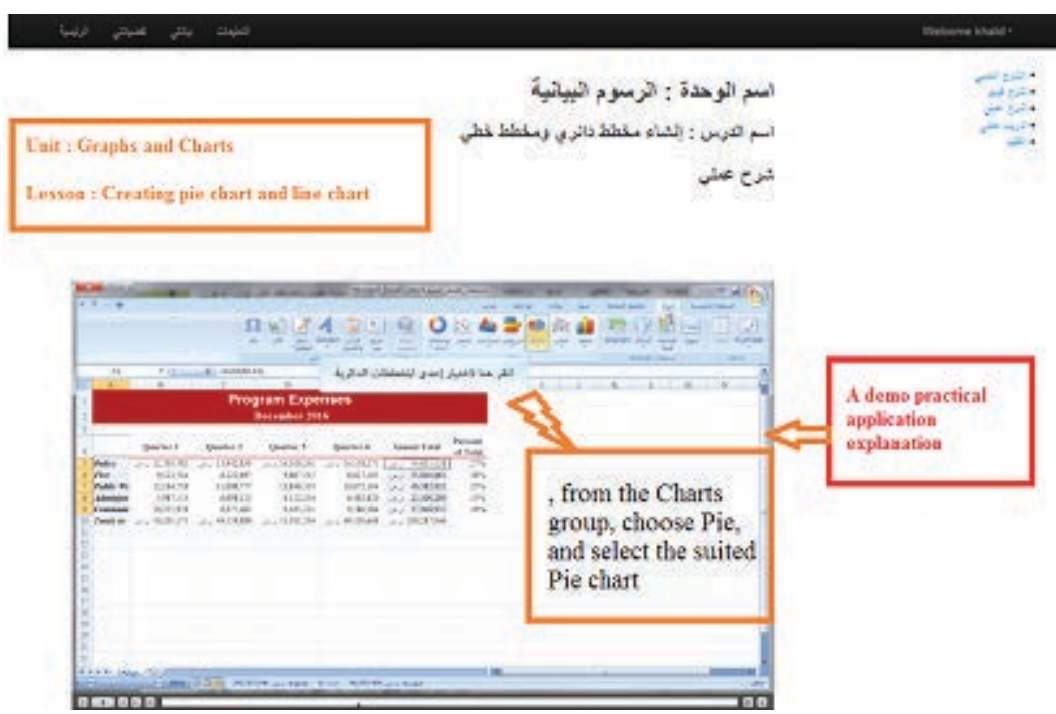

Figure 8. Practical demo showing the steps for creating the pie chart lesson

Wa

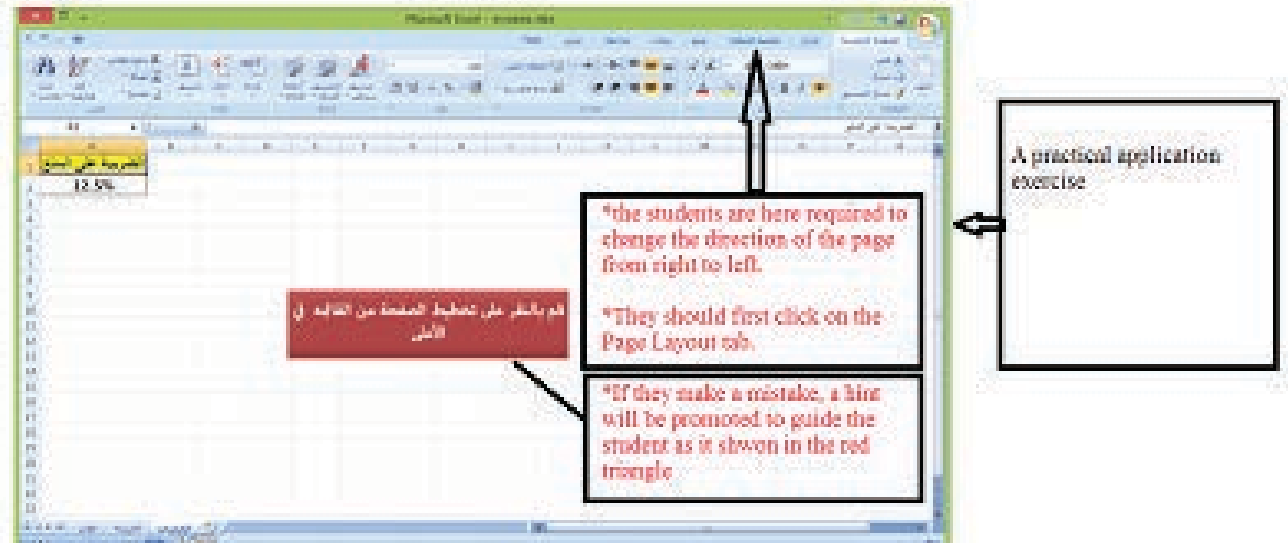

Figure 9. Practical exercise showing the steps for changing the chart direction (when students respond incorrectly) 

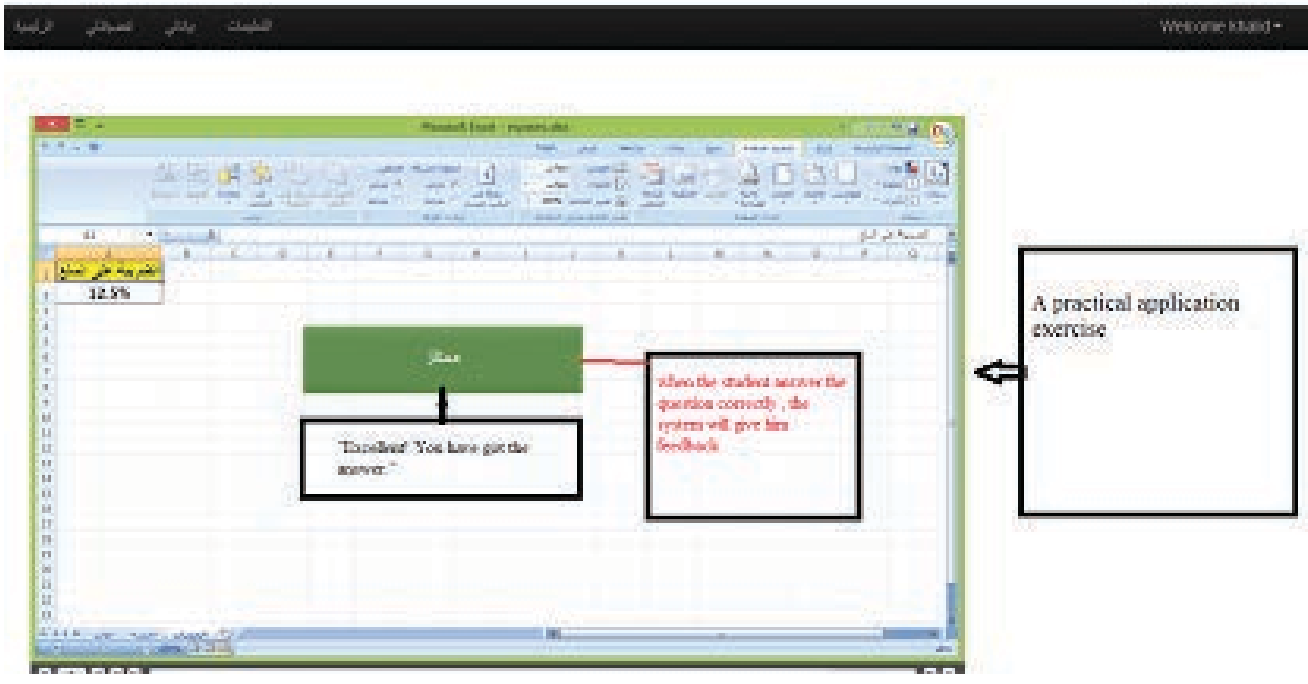

Figure 10. Practical exercise showing the steps for changing the chart direction (when students respond correctly)

Page Layout tab. If they make a mistake, a hint will be promoted to guide the student, as shown in Figure 9. The red triangle directs students to click the Page Layout tab (three attempts are allowed for the student per each step). When they click on the right answer, such as the second step of clicking the Sheet Right-to-Left button from the sheet option, the program will give them feedback such as "Excellent! You have got the answer." (See Figure 10).

4. The following figure (Figure 11) contains a video from the lecturer explaining the lesson on creating a pie chart and line chart.

5. This is an assessment exercise through which students can receive feedback; in it, they are able to see whether their answer is correct or not. This is different from the practical exercise in that here the hints will not be available for the students. This exercise will give students just one attempt and then provide feedback about whether the answer is correct or not (see Figure 12).

The main objective of the conducted experiments was to compare the effectiveness of the proposed IT2FLS system to the type-1 fuzzy logicbased counterpart system (T1FLS), the instructorled adaptive system and the nonadaptive version of the system, in regard to enhancing the quality of instruction, promoting better student performance, and increasing success rates.
The experiment started with the formation of four groups from the 1,458 students in the study, and each group was randomly and equally assigned distance e-learners. During the initial monitoring phase, the learners registered and took a comprehensive preassessment test to measure their current knowledge of Excel and PowerPoint. The average scores for these two preassessment tests were collected, along with the students' gender, age, secondary school grade and whether they were full- or part-time students, and their course of study in secondary school to form the seven inputs for the fuzzy systems. Subsequently, we deliberately revealed the average assessment results to the students to enable them to determine the appropriate content for their level and preference. Four outputs were collected from the students: the difficulty level they needed for Excel and PowerPoint, time needed for Excel, and time needed for PowerPoint.

Once the inputs and outputs of the proposed model were collected, the interval type- 2 fuzzy logic system was constructed using the fuzzy sets to generate rules (see Figure 13) as explained in section 5.2.1. The interval type-2 fuzzy sets were obtained to handle and capture the uncertainty that signifies learners' views about modeling a particular linguistic label to determine learner characteristics and instructional needs. Figure 14 shows the interval type- 2 fuzzy sets as solid red lines and the type-1 fuzzy sets as yellow dashed lines. The interval type-2 fuzzy sets were constructed from a sample of 30 students by asking their views about modeling such a set. 

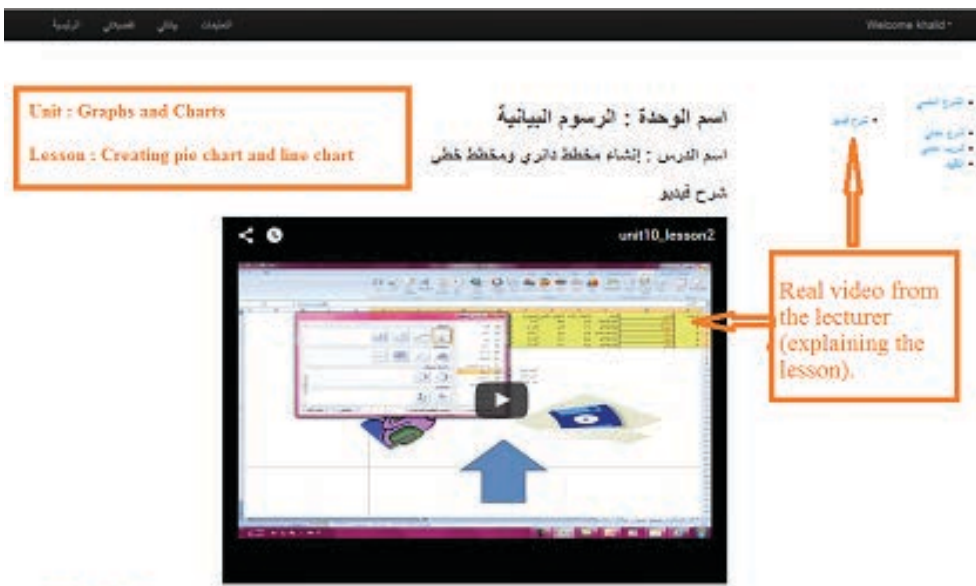

Figure 11. Lecturer video interface for creating the pie chart lesson
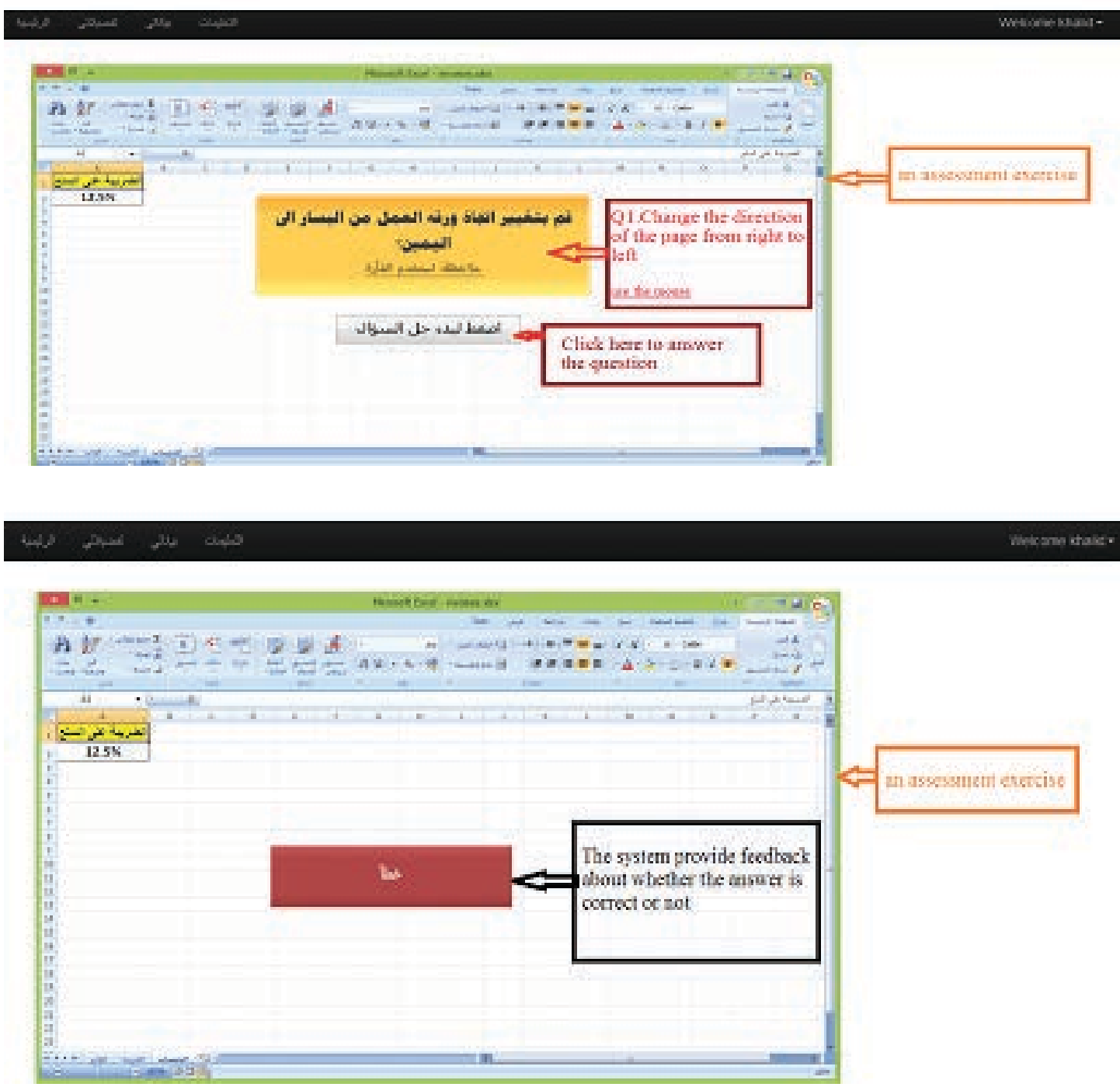

Figure 12. Assessment exercise interfaces (with system feedback about whether the answer is correct or not) 
IF Student-Age is Teen $A N D$ Student-Gender is Female $A N D$ Secondary-Grade is Excellent $A N D$ Method-of-Providing-Higher-Education is Full-Time $A N D$ the Secondary-Section is Science $A N D$ Average-Knowledge-in-Excel is Very Low $A N D$ Average-Knowledge-in-PowerPoint is Low, then the Suited-Excel-Difficulty-Level is Easy $A N D$ Needed-Time-to-Study-Excel is Very Long $A N D$ Suited-PowerPointDifficulty-Level is Moderate $A N D$ Needed-Time-to-Study-PowerPoint is Short.

Figure 13. One example of an extracted rule from the produced rules

Very Easy

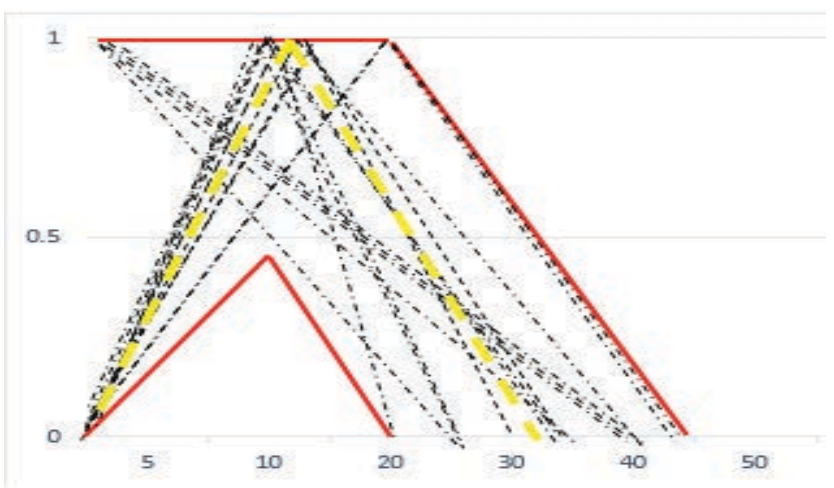

Figure 14. An example of the extracted interval type-2 fuzzy set (very easy) of the suitable required difficulty level (thick solid lines) and the type-1 fuzzy sets (thick dashed lines) 
In the second phase, the course contents of Excel and PowerPoint, were delivered as required for a third group, which used a system based on type1 fuzzy logic, and a fourth group, which used the system based on the applied interval type-2 fuzzy logic system. Meanwhile, the first group continued its studies using the nonadaptive version of the system, while the second group used the instructor's led adaption model with fixed rules based on expert guidance. Thus, the third and fourth groups were presented with adaptive, tailored learning content that was matched to their preferences and needs according to the rules derived from various students using the system. Students were presented with learning objects (LOs) according to their knowledge-delivery needs and preferences. Each LO in the lesson, such as Conditional Formatting in Excel, was associated with two linguistic values, which corresponded to the difficulty of Excel content and whether the user preferred to spend more time studying Excel topics. Each of the more than 63 lessons had the features mentioned above for each of the two subjects, Excel and PowerPoint, and the content ranged from very easy to very difficult with different amounts of time to spend on each lesson. Once this phase was completed, we analyzed the results to assess performance after the students finished the term.

The results from the knowledge delivery system based on the applied IT2FLS environment, the type1 fuzzy system, the system with fixed rules, and the nonadaptive version of the system were compared with one another. Figure 15 shows the improvement in the average scores for each group by looking at their scores prior to and after the application of each system. As clearly shown in Figure 15 , there is a significant increase in the average scores of the students using the IT2FLS (26.04\%), which represents the best performance of the four study groups. The employment of the T1FLS increased the average scores by $23.78 \%$, while the instructors' lead adaptive system and the nonadaptive version (controlled Group) increased performance by $20.48 \%$ and $19.06 \%$, respectively.

In addition, the completion rate for the four groups was obtained (see Figure 16). The total number of students who completed at least $90 \%$ of the lessons with the interval type- 2 adaptive educational system was greater than the number of students who studied with the type-1 fuzzy system by $1.62 \%$, and was greater than the instructors' lead adaptive system by $9.48 \%$, and greater than the nonadaptive-based system by $10.65 \%$. The improvement in the students' learning outcomes and completion rates evidences the effectiveness of the proposed IT2FLS adaptive educational system as compared to other methods.

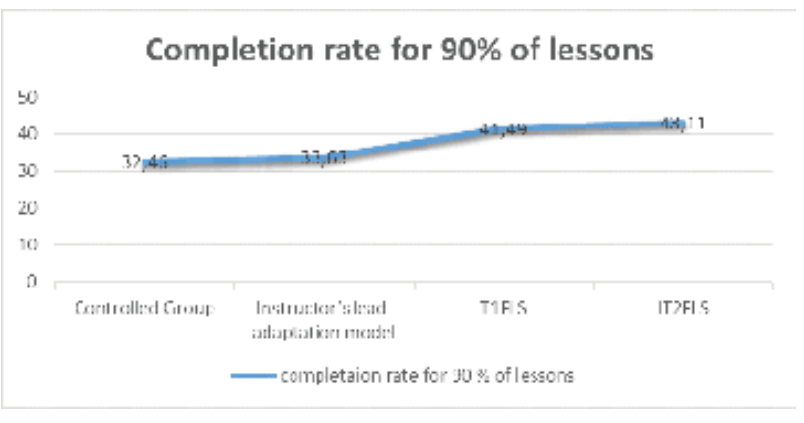

Figure 16. The completion rate obtained by each of the four groups of students in the two study subjects after the application of each system

In addition, Table 1 shows the average error and standard deviation for the system outputs obtained. The total number of the collected dataset was 960 instances. The data set was then split into a training and testing data set consisting of 672 and 288 instances respectively. These results demonstrate that the IT2FLS system produces a lower average error rate and standard deviation of errors than the type-1 fuzzy logic system when comparing the system outputs and student-desired outputs. This means that the IT2FLS type-2 fuzzy system is more effective in capturing student behavior.

\section{Conclusions and Future Work}

In this paper, we presented an interval type-2 fuzzy logic-based system that can learn different users' pedagogical needs and preferences based on their knowledge level as well their characteristics in a dynamic online environment. This model was applied to enhance student outcomes and completion rates by presenting students with tailored, adaptive content that matches their needs.

The IT2FLS was tested and compared to the T1FLS, the instructors' lead adaptive system and a nonadaptive system. The experiments were con- 


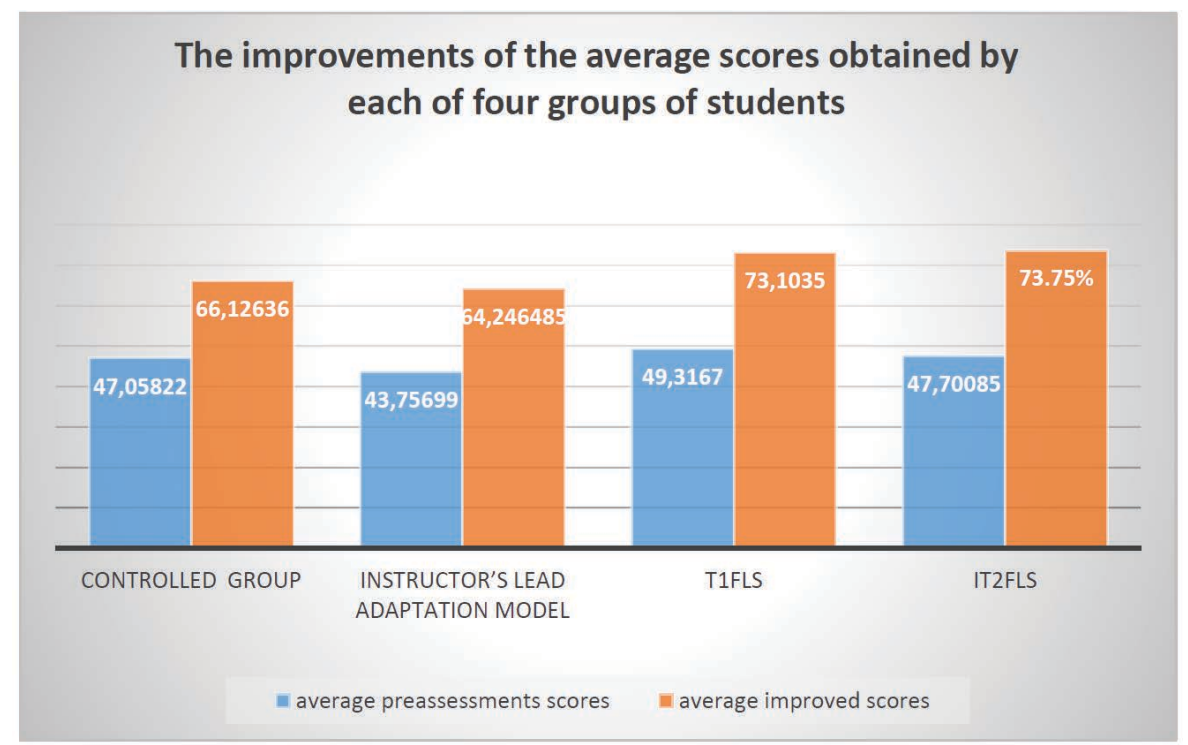

Figure 15. The improvement in the average scores obtained from each of the four study groups prior to and after the application of each system

Table 1. Average error and standard deviation of the system outputs

\begin{tabular}{|l|l|l|l|l|}
\hline Output & T1FLS & T2FLS \\
\hline & Average error & $\begin{array}{l}\text { Standard de- } \\
\text { viation }\end{array}$ & Average error & $\begin{array}{l}\text { Standard de- } \\
\text { viation }\end{array}$ \\
\hline $\begin{array}{l}\text { Level of difficulty needed for } \\
\text { studying Excel }\end{array}$ & 30.104 & 23.424 & 28.589 & 20.291 \\
\hline Needed time for studying Excel & 32.130 & 26.131 & 28.758 & 21.831 \\
\hline $\begin{array}{l}\text { Level of difficulty needed for } \\
\text { studying PowerPoint }\end{array}$ & 29.638 & 23.372 & 28.761 & 20.724 \\
\hline $\begin{array}{l}\text { Needed time for studying Pow- } \\
\text { erPoint }\end{array}$ & 31.520 & 25.740 & 29.358 & 22.732 \\
\hline
\end{tabular}


ducted within a massively crowded e-learning platform with a population of 1458 students from King Abdulaziz University. The results revealed that IT2FLS was better able to handle uncertainties, producing lower average errors and standard deviation. This resulted in an increased completion rate over the T1FLS group by $1.62 \%$, over the instructor's lead adaption model by $9.48 \%$, and over the controlled group by $10.65 \%$. In addition, this improved students' performance for the IT2FLS group was over the performance improvement achieved by T1FLS group by $2.26 \%$ and over the instructor's lead adaption model by $5.56 \%$, and over the controlled group by $6.98 \%$

Thus, these promising results from the proposed system facilitate instruction with better delivery. In the future, we aim to employ general z-slices type-2 fuzzy logic systems to be better able to handle uncertainties in the model. We also aim to deploy the proposed system for more e-learning courses with more inputs and outputs that will include thousands of students.

\section{Acknowledgement}

This work was supported by the NSTIP strategic technologies program in the Kingdom of Saudi Arabia - Project No. (12-INF2259-03). The authors also, acknowledge with thanks Science and Technology Unit, King Abdulaziz University for technical support.

\section{References}

[1] LA. James, Evaluation of an Adaptive Learning Technology as a Predictor of Student Performance in Undergraduate Biology, (Master's thesis), Appalachian State University, North Carolina,USA, May 2012.

[2] B. Bloom, The 2 sigma problem: The search for methods of group instruction as effective as one-toone tutoring, Educ. Res., vol. 13, pp. 4-16, 1984.

[3] T. Kidd, Online Education and Adult Learning: New York: Hershey, 2010.

[4] M. Vandewaetere, P. Desmet, and G. Clarebout, The contribution of learner characteristics in the development of computer-based adaptive learning environments, Computers in Human Behavior, vol.27, No.1, pp.118-130, 2011.
[5] Ambient Insight, Learning Technology Research Taxonomy Research Methodology, Buyer Segmentation, Product Definitionsand Licensing Model, Ambient Insight Research, 2012.

[6] B. Ciloglugil, and M. Inceoglu, User Modeling for Adaptive E-Learning Systems, Computational Science and Its Applications-ICCSA 2012, vol.7335, pp.5561, 2012.

[7] F. Essalmi, L. J. B. Ayed, M. Jemni, Kinshuk, and S. Graf, A fully personalization strategy of Elearning scenarios, Computers in Human Behavior, Elsevier, vol.26, No.4, pp.581-591, 2010.

[8] V. J. Shute, and D. Zapata-Rivera, Adaptive educational systems, In P. Durlach (Ed.), Adaptive technologies for training and education (pp. 7-27). New York, NY: Cambridge University Press, 2012.

[9] White paper based upon the Speak Up 2011 national findings, Leveraging Intelligent Adaptive Learning to Personalize Education, Intelligent Adaptive Learning : Speak Up Reports, 2012.

[10] C. Martins, L. Faria, and E. Carrapatoso, An Adaptive Educational System For Higher Education, Proceedings of the 14th EUNIS 08 International Conference of European University Information Systems, Denmark, 24 - 27 of June, 2008.

[11] A. Ahmad,O. Basir, and K. Hassanein,Adaptive user interfaces for intelligent e-Learning: issues and trends, In Proceedings of the Fourth International Conference on Electronic Business (ICEB2004), Xiyuan Hotel, Beijing, China, pp. 925-934, December 5-9, 2004.

[12] J. M. Mendel, Uncertain Rule-Based Fuzzy Logic Systems: Introduction and New Directions, Prentice Hall PTR, Prentice Hall Inc, 2001.

[13] E. Frias-Martinez, G. Magoulas, S. Chen, and R Macredie, Recent soft computing approaches to user modeling in adaptive hypermedia, In Adaptive Hypermedia and Adaptive Web-Based Systems, pp. 31-55, Springer Berlin/Heidelberg, 2004.

[14] A. Gertner, and K.VanLehn, Andes: A coached problem solving environment for physics, In Intelligent Tutoring Systems, vol.1839, pp. 133-142, Springer Berlin/Heidelberg, 2000.

[15] N. Idris, N. Yusof, and P. Saad, Adaptive course sequencing for personalization of learning path using neural network, International Journal of Advanced Soft Computing Applications, vol. 1, pp. 49-61, 2009.

[16] H. Seridi-Bouchelaghem, T. Sari, and M. Sellami, A Neural Network for Generating Adaptive Lessons, Journal of Computer Science 1, no. 2, pp.232-243, 2005. 
[17] R. Sripan and B. Suksawat, Propose of Fuzzy Logic-Based Students' Learning Assessment, Proceedings in the International Conference on Control, Automation and Systems, pp. 414-417, Gyeonggi-do, Korea, October 2010.

[18] J. Ma and D. N. Zhou, Fuzzy set approach to the assessment of student centered learning, IEEE Trans. Educ., vol. 33, pp. 237-241, May 2000.

[19] S. Venkatesan, and S. Fragomeni, Evaluating learning outcomes in PBL using fuzzy logic techniques, 19th Annual Conference of the Australasian Association for Engineering Education: To Industry and Beyond; Proceedings of the Institution of Engineers, Australia, 2008.

[20] D. Xu, H. Wang and K. Su, Intelligent student profiling with fuzzy models, in Proceedings of the 35th Hawaii International Conference on System Science (HICSS 2002), January, Hawaii, U.S.A, 2002.

[21] H.J. Cha, Y.S. Kim, S.H. Park, T.B. Yoon, Y.M. Jung, and J.-H. Lee, Learning Style Diagnosis Based on User Interface Behavior for the Customization of Learning Interfaces in an Intelligent Tutoring System, Proceedings of the 8th International Conference on Intelligent Tutoring Systems, Lecture Notes in Computer Science, Berlin, Heidelberg, Springer, Vol. 4053, pp. 513-524, 2006.

[22] F. Moreno, A. Carreras, M. Moreno and E. R. Royo, Using Bayesian Networks in the Global Adaptive E-learning Process, EUNIS 2005, Manchester, pp. 1-4,2005

[23] S. Gutierrez-Santos, J. Mayor-Berzal,C. Fernandez-Panadero, and CR. Kloos, Authoring of Probabilistic Sequencing in Adaptive Hypermedia with Bayesian Networks, Journal of Universal Computer Science 16, no. 19, pp.2801-2820, 2010.

[24] R. Stathacopoulou, M. Grigoriadou, M. Samarakou, and D. Mitropoulos, Monitoring students' actions and using teachers' expertise in implementing and evaluating the neural networkbased fuzzy diagnostic model, Expert Systems with Applications, Elsevier, 32, pp. 955-975, 2007.

[25] A. Jameson, Numerical uncertainty management in user and student modeling: An overview of systems and issues, Use Modeling and User-adapted Interaction, vol. 5(3-4), pp. 103-251, 1996.
[26] A. Kavi, R. Pedraza-Jimnez, H. Molina-Bulla, F.J. Valverde-Albacete, J. Cid-Sueiro, and A. NaviaVzquez, Student Modelling Based on Fuzzy Inference Mechanisms, Proceedings of the IEEE Region 8 EUROCON 2003, Computer as a Tool, Ljubljana, Slovenia, September 2003.

[27] A. Kavi, Fuzzy user modeling for adaptation in educational hypermedia, IEEE Trans. Syst., Man, Cybern. C, Appl. Rev., vol. 34, no. 4, pp. 439-449, Nov. 2004.

[28] F. Liu, and J. Mendel, An interval approach to Fuzzistics for intervaltype-2 fuzzy sets, Proceedings of the 2007 IEEE InternationalConference on Fuzzy Systems, London, UK, pp. 1030-1035.

[29] K. Almohammadi, B. Yao, and H. Hagras, An interval type-2 fuzzy logic based system with user engagement feedback for customized knowledge delivery within intelligent E-learning platforms, Proceedings of the 2014 IEEE International Conference on Fuzzy Systems, 2014, pp. 808-817.

[30] K. Almohammadi and H. Hagras, An Interval Type-2 Fuzzy Logic Based System for Customised Knowledge Delivery within Pervasive E-Learning Platforms, Proceeings of the 2013 IEEE International Conference on Systems, Man, and Cybernetics, 2013, pp. 2872-2879.

[31] K. Almohammadi, H. Hagras, B. Yao, A. Alzahrani, D.Alghazzawi, and G. Aldabbagh, A Type-2 Fuzzy Logic Recommendation System for Adaptive Teaching, Journal of Soft Computing, August 2015.

[32] L. X. Wang, The MW method completed: A flexible system approachto data mining, IEEE Transactions on Fuzzy Systems, vol. 11, no. 6, pp. 768782, December 2003.

[33] H. Hagras, F. Doctor, A. Lopez and V.Callaghan, An incremental adaptive life long learning approach for type-2 fuzzy embedded agents in ambient intelligent environments, IEEE Transactions on Fuzzy Systems, vol. 15, no. 1, pp. 41-55, February 2007.

[34] K. Almohammadi and H. Hagras, An adaptive fuzzy logic based system for improved knowledge delivery within intelligent E-Learning platforms, Proccedings of the the 2013 IEEE International Conference on Fuzzy Systems, 2013, pp. 1-8. 


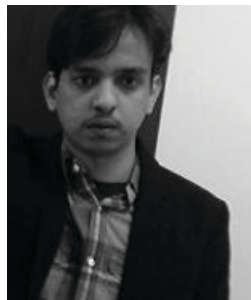

Khalid Almohammadi completed his bachelor's degree in computer science from Taibah University in the Kingdom of Saudi Arabia. He then pursued a profession in teaching at Tabuk University. Building on this experience, he was awarded a scholarship to complete his master's in computer science (MSc) at Newcastle University in England, which he obtained with distinction in 2011. He is currently in the process of completing his $\mathrm{PhD}$ in computer science at Essex University in England, which incorporates all his previous knowledge and experience in education and e-learning. The focus of his research is the development of theoretical and practical environments to enhance the learning experience and engagement by using fuzzy logic systems.

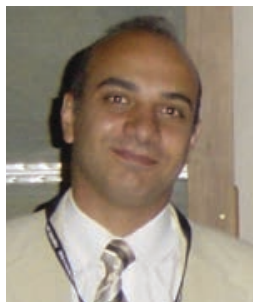

Hani Hagras received the B.Sc. and M.Sc. degrees in electrical engineering from Alexandria University, Alexandria, Egypt, and the Ph.D. degree in computer science from the University of Essex, Colchester, U.K. He is a Professor in the School of Computer Science and Electronic Engineering, Director of the Computational Intelligence Centre and the Head of the Fuzzy Systems Research Group in the University of Essex, UK. His major research interests are in computational intelligence, notably type- 2 fuzzy systems, fuzzy logic, neural networks, genetic algorithms, and evolutionary computation. His research interests also include ambient intelligence, pervasive computing and intelligent buildings. He is also interested in embedded agents, robotics and intelligent control. He has authored more than 300 papers in international journals, conferences and books. He is a Fellow of the Institute of Electrical and Electronics Engineers (IEEE) and he is also a Fellow of the Institution of Engineering and Technology (IET (IEE). He was the Chair of IEEE Computational Intelligence Society (CIS) Senior Members Sub-Committee. His research has won numerous prestigious international awards where most recently he was awarded by the IEEE Computational Intelligence Society (CIS), the 2013 Outstanding Paper Award in the IEEE Transactions on Fuzzy Systems and he was also awarded the 2006 Outstanding Paper Award in the IEEE Transactions on Fuzzy Systems. He is an Associate Editor of the IEEE Transactions on Fuzzy Systems. He is also an Associate Editor of the International Journal of Robotics and Automation, the Journal of Cognitive Computation and the Journal of Ambient Computing and Intelligence. He is a member of the IEEE
Computational Intelligence Society (CIS) Fuzzy Systems Technical Committee and IEEE CIS conference committee. Prof. Hagras chaired several international conferences where he served as the General Co-Chair of the 2007 IEEE International Conference on Fuzzy systems London.

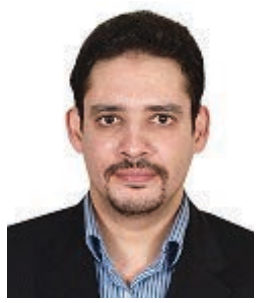

Daniyal Alghazzawi obtained his Bachelor's degree with honor in Computer Science from King Abdulaziz University (KAU) in 1999. He completed his Master's degree and Doctorate in the field of Computer Science at the University of Kansas at the United States in 2007. He also obtained another Master's degree in Teaching and Leadership from University of Kansas in 2004. He also obtained the certificate of Management International Leadership (LMI) and has been the Head of the Information Systems department, Faculty of Computing and Information Technology for over five years during which he organized many workshops, and international and domestic conferences. He is currently an Associate Professor in the Department of Information Systems, Faculty of Computing \& Information Technology at King Abdulaziz University. He is also the head of the Information Security Research Group at King Abdulaziz. He has published 60 papers in various international journals, conferences and books in the field of Intelligent Systems and Information Security. His research interests include intelligent environments, computational intelligence, Smart e-Learning and Information Security.

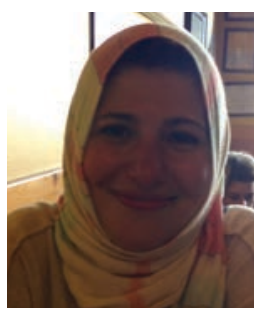

Ghadah Aldabbagh received her BSc in 1991 in Electrical Engineering (Computer Engineering Specialization) from the University of Illinois at Urbana - Champaign, Illinois, United States. She received her MSc in the Data Communication Networks and Distributed System (DCNDS) Program in the Computer Science Department, University College London (London), United Kingdom (UK), then she received her PhD in 2010 from the Department of Electronic and Electrical Engineering from the University College London (UCL), United Kingdom (UK). She holds an Assistant Professor position at the Faculty of Computing and Information Technology in the Computer Science Department at King Abdul Aziz University. Her research covers Communication Systems and Networks, Networking Algorithms and Performance Evaluation and Protocols and Algorithms. 